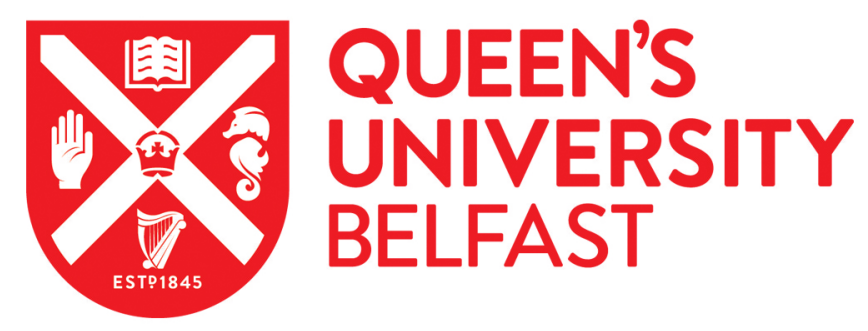

\title{
The mental health and help-seeking behaviour of children and young people in care in Northern Ireland: Making services accessible and engaging
}

Fargas-Malet, M., \& McSherry, D. (2018). The mental health and help-seeking behaviour of children and young people in care in Northern Ireland: Making services accessible and engaging. British Journal of Social Work, 48(3), 578-595. https://doi.org/10.1093/bjsw/bcx062

Published in:

British Journal of Social Work

Document Version:

Peer reviewed version

Queen's University Belfast - Research Portal:

Link to publication record in Queen's University Belfast Research Portal

Publisher rights

Copyright 2017 The Authors and Oxford University Press.

This work is made available online in accordance with the publisher's policies. Please refer to any applicable terms of use of the publisher.

\section{General rights}

Copyright for the publications made accessible via the Queen's University Belfast Research Portal is retained by the author(s) and / or other copyright owners and it is a condition of accessing these publications that users recognise and abide by the legal requirements associated with these rights.

\section{Take down policy}

The Research Portal is Queen's institutional repository that provides access to Queen's research output. Every effort has been made to ensure that content in the Research Portal does not infringe any person's rights, or applicable UK laws. If you discover content in the

Research Portal that you believe breaches copyright or violates any law, please contact openaccess@qub.ac.uk. 


\title{
The mental health and help-seeking behaviour of children and young people in care in Northern Ireland: Making services accessible and engaging
}

\begin{abstract}
Largely as a result of early adverse experiences, children and young people in care are more likely to suffer from mental health difficulties than their peers. Despite these difficulties, they tend to find it hard to seek help and engage with professional services to address their needs. In Northern Ireland, the Mind Your Health study collected data for 233 children and young people in care through phone interviews with their carers, and 25 of these young people were interviewed. Focus groups with professionals were also carried out. According to their carers, 35\% had diagnosed emotional difficulties, and 36\% scored in the abnormal range for the Strengths and Difficulties Questionnaire’s emotional symptoms scale. Carers described difficulties in accessing mental health services for young people, due to lengthy waiting lists, a lack of information offered, and a lack of effort to engage them. Young people found it difficult to engage with these services because of their feelings of stigma, embarrassment, insecurity, guilt and fear. Some felt unable to seek help even from their families and friends. We recommend that mental health services are made more locally accessible, waiting times are reduced, with a greater emphasis on proactive outreach work.
\end{abstract}

Key words: Looked after children, mental health, help-seeking, service users

\section{Introduction}

Young people (aged 12 to 24) have been found to be at higher risk than other age groups to suffer from mental health problems (Patel, Flisher, Hetrick, \& McGorry, 2007). In turn, certain groups of young people appear particularly vulnerable to experience mental ill health. One of these groups is children and young people living in care, the majority of whom will 
have experienced some form of abuse and/or neglect from an early age. A plethora of studies have found that children in care have considerably higher levels of psychological problems than their peers (Egelund \& Lausten, 2009; Ford, Vostanis, Meltzer, \& Goodman, 2007; Lehmann, Havik, Havik, \& Heiervang, 2013; McCrystal \& McAloney, 2010; Meltzer, Corbin, Gatward, Goodman, \& Ford, 2003; Meltzer, Lader, Corbin, Goodman, \& Ford, 2004a, 2004b; Oswald, Heil, \& Goldbeck, 2009; Sempik, Ward, \& Darker, 2008; TarrenSweeney, 2008; Teggart \& Menary, 2005). Even within the care population, some groups appear to be more likely to experience emotional and behavioural difficulties than others, including those with learning disabilities (Taggart, Cousins, \& Milner, 2007), those who move placement frequently (Beck, 2006a); and those living in residential care (Ford et al., 2007; Tarren-Sweeney, 2008).

Despite young people being more likely to have mental health and substance abuse problems than other age groups, only a minority receive mental health care or are formally diagnosed (Anderson \& Lowen, 2010; Zwaanswijk, Verhaak, Bensing, van der Ende, \& Verhulst, 2003). This is because the demand for these services exceeds capacity, with current services in the UK being over-stretched and fragmented (Faulconbridge, Gravestock, Laffan et al., 2016), but also because around three quarters of children and young people with psychological difficulties do not make contact with services (Green, McGinnity, Meltzer et al., 2004), many being reluctant to seek help regarding their mental health (Rickwood, Deane, \& Wilson, 2007; Rothi \& Leavey, 2006). Children in care, despite being more likely to display poor mental health than their peers, have also been found to experience significant difficulties accessing mental health services (Beck, 2006b; Vostanis, Bassi, Meltzer, Ford, \& Goodman, 2008). This is concerning, as these young people need to be able to seek help and engage with appropriate services in order to improve their emotional wellbeing. Help-seeking is a vital step in improving mental health and accessing a suitable source of care. It requires 
an awareness of the problem, and the ability and willingness to articulate the problem and the need for help, as well as to choose a source of help (Kauer, Mangan, \& Sanci, 2014; Rickwood et al., 2007).

Young people are reticent about seeking help for their mental health problems due to a range of factors. A recent literature review found stigma to have a clear (although small to moderate) negative effect on help-seeking for mental health problems (Clement, Schauman, Graham et al., 2015). In addition to stigma and embarrassment, barriers to help-seeking include: poor mental health literacy and/or denial of the existence of a problem; self-reliance (i.e. belief that they can/should be able to sort out their own problems on their own); poor accessibility (in terms of time, transport or cost); lack of knowledge about/familiarity with mental health services; fear about the help-seeking process or the source of help (e.g. that the practitioner will reprimand them or ask difficult questions); concern about the characteristics of the provider (e.g. their ability to offer the right help) or negative perception of the source of help (e.g. belief that treatment would not help); fear about lack of confidentiality regarding the source of help; and insufficient youth-related training for health care practitioners (Anderson \& Lowen, 2010; Gulliver, Griffiths, \& Christensen, 2010; Tylee, Haller, Graham, Churchill, \& Sanci, 2007; Vanheusden, Mulder, van der Ende et al., 2008). Although there is not much research on the barriers to help-seeking specifically for young people in care, the existing evidence seems to point to these same barriers mentioned (Beck, 2006b; Samuels \& Pryce, 2008), in addition to others, such as the mobility of children within the care system, leading to difficulties in building trusting relationships (Golding, 2010).

Since 2000, mental health services in the UK have been structured through multiple specialist teams, with a different team responsible for each incident of care (inpatient team, crisis team, community team). In England, that has been in parallel with the introduction of the New Ways of Working (NWW) programme, which is part of the National Institute for Mental 
Health (NIMHE), initially focused on the consultant psychiatrist but progressed to the rest of the mental health workforce. NWW advocates for "a model where responsibility is distributed amongst team members rather than delegated by a single professional, such as the consultant”, and it "enables qualified staff to extend their practice” (DH, 2007, p.14). In Northern Ireland, the Department published a service model document for children and adolescent mental health services (CAMHS) in July 2012, setting a framework against which to remodel CAMH service provision, and promote an improved and more consistent approach across all Health and Social Care Trust areas (DHSSPS, 2012). This model proposed a stepped care approach, which aimed to deliver the right level of care in a timely way. However, one of the unintended by-products of this restructuring has been a diminution in continuity of care, which has been experienced by young people as disruptive and damaging (with repetitive questioning, multiple assessments, and difficult transitions between services) (Plaistow, Masson, Koch et al., 2014). In addition, young people experience an additional transition from CAMHS (for under 18 year olds) to adult mental health services, a transition which is often poorly planned, inadequately executed and experienced in a negative way (Singh, Paul, Ford et al. 2010). Because of their high risk for mental health difficulties and the problems faced by CAMHS in providing a flexible, sensitive and accessible service, many have argued for "dedicated mental health services for children in care, in recognition of their differing circumstances, and the need for effective inter-agency working for this specialist population” (Golding, 2010, p. 575). There are dedicated mental health services for children in care in each of the five Health and Social Care Trusts (similar to local authorities in England and Wales) in Northern Ireland, but there has been a lack of research on interagency working for this population, and how this service provision is viewed and experienced by the young people themselves and their carers. 
This article provides an outline of the mental health needs of children and young people in care in Northern Ireland, explores the barriers that they experience to help-seeking, and presents their views, together with those of their carers and social work practitioners, on what would best enable their engagement with services, and ultimately improve their emotional wellbeing.

\section{The study}

The Mind Your Health study aimed to outline the health problems of children and young people in care in Northern Ireland, and to explore how their health needs were being addressed. This cross-sectional study used a mixed-methods approach, which included: a review of policy and practice documents; focus group interviews with senior social work managers in each of the five Health and Social Care Trusts; 233 telephone interviews with carers (foster, kinship and residential); 25 semi-structured interviews with young people; and multi-disciplinary focus group interviews with professionals across the HSC Trusts. This paper focuses on the data gathered on mental health needs and service provision from the practitioners, carers and the young people themselves. A more general profile is provided elsewhere (McSherry, D., Fargas Malet, M., McLaughlin, K. et al., 2015).

\section{Methods}

\section{Ethical approval}

Each of the five HSC Trusts gave research governance approval, and the Office of Research Ethics Committee in Northern Ireland (ORECNI) awarded ethical approval for the study. All participants in the study gave informed consent. 
Focus groups with social work practitioners

We carried out five focus groups, one in each HSC Trust, with social work managers, senior practitioners, and senior social workers for Looked After children, fostering, and residential services. We asked the HSC Trusts to identify those individuals who would have particular experience in relation to meeting the health needs of LAC. These were then identified by the Trusts themselves, and focus groups arranged by them. The focus group interview was designed to ascertain participants' views on how the HSC Trusts were meeting the health needs of children and young people in care, what facilitated or obstructed implementation, gaps in service provision, and suggestions on how to make things better.

Phone interviews with carers

We aimed to interview the carers of ten per cent of all 2,500 children and young people in care in Northern Ireland. Each HSC Trust specified its population of LACYP, as of $31^{\text {st }}$ August 2013, using the Social Services Client and Administration Retrieval Environment (SOSCARE). Research collaborators in each Trust facilitated the consent process for gaining the telephone number of the carers and birth parents (of children living at home on a care order) agreeable to take part. We conducted 233 telephone interviews with carers regarding a particular child for whom they were caring (see Table 1 for characteristics of the sample). This interview involved the collection of quantitative and qualitative data. It lasted approximately 45 minutes and included questions regarding: i) the medical information they received when the child/young person was placed with them (including historical health information); ii) their perception of the child/young person's health needs; iii) the impact of past and current assessments to attend these needs; and iv) any other health services they were given. The questionnaire included the Strengths and Difficulties Questionnaire (SDQ) (Goodman, 1997), an adapted version of the Warwick Child Health and Morbidity Profile 
(WCHMP) (Anderson, Spencer, \& Vostanis, 2004), and questions from the Young People’s Behaviour and Attitude Survey (YPBAS) (NISRA, 2014).

\section{[Insert Table 1 here]}

\section{Interviews with young people}

If the young person was 12 years or older, researchers asked carers who had completed the telephone interview if they agreed for the child/young person to be sent an information sheet and invitation letter to take part in a face-to-face interview. We interviewed 25 young people, who agreed to be interviewed. Two researchers went to their homes to carry out the face-toface interview, as requested by the Office of Research Ethics Committee in Northern Ireland (ORECNI) in order to protect the researchers and the young people. They asked the young people about their understanding of their health and their experience of help-seeking and supports. The names of the young people given in the results section are pseudonyms.

\section{Analysis}

All interviews (with practitioners, carers and young people) were digitally recorded, transcribed, and analysed using content analysis. Thus, we scrutinised the transcriptions for recurring themes, and identified and developed detailed codes, which were input in excel sheets. The codes identified related to a range of issues, and this included help-seeking, barriers to help-seeking, and suggestions to improve services. Within these themes, some of the codes developed were: young people’s lack of engagement with services; young people’s negative feelings of stigma, insecurity, guilt and fear; structural challenges (including difficulties in accessing services, long waiting lists, and resource issues); and gaps in service provision.

The quantitative data from the telephone interviews with carers were input into an SPSS file, and a series of descriptive statistics (i.e. cross-tabulations, frequencies, means and standard 
deviations) were conducted in order to analyse the data. Pearson Chi-Square tests and oneway Analysis of Variance (ANOVA) were utilised to examine the relationship between background variables and health profile variables.

\section{Findings}

\section{Mental health of children and young people in care in Northern Ireland}

Mental health problems featured significantly in this study, being extensively reported by professionals, carers and young people. For instance, mental health was one of the key topics examined within each of the five initial focus groups with social work practitioners. Participants highlighted the prevalence of mental health difficulties, in addition to alcohol and drug abuse, for children and young people in care, especially for those in residential care, but also for those in the older age groups, who were about to leave care.

The carers of 204 children over three years old completed the Strengths and Difficulties Questionnaire for each child. We found that 36\% scored within the abnormal range on the emotional symptoms scale. Both the type of placement $(F(2,197)=3.24, p=.04)$, and the child/young person's age $\left(X^{2}(12, N=206)=29.37, p=.01\right)$ were significantly related to emotional symptoms scores. In terms of placement type, children in residential care were more likely to score higher in the SDQ emotional symptoms scale than children in kinship care. To be precise, $50 \%$ of children in residential care scored in the abnormal range, compared to $37 \%$ of children in foster care and $23 \%$ of children in kinship care. Regarding age, the older the children were, the more likely they were to score higher in the SDQ emotional symptoms scale, with 50\% of children aged 18 years and over scoring in the abnormal range compared to $30 \%$ of children aged 5-11 years.

The study questionnaire included a comprehensive list of previous and ongoing health conditions for this group of children and young people. According to their present carers, 
35\% of children/young people had been diagnosed with emotional problems (which corresponds with the findings from the SDQ), and a further $15 \%$ were suspected to have emotional problems (undiagnosed). Diagnosed emotional problems also multiplied with age $\left(X^{2}(15, N=233)=50.45, p=.001\right)$, with the 18 years and over category having the highest percentage for the group as a whole (58\%; compared to $11 \%$ for $1-4$ year olds, $29 \%$ for $5-11$ year olds, $41 \%$ for $12-15$ year olds, and $51 \%$ for $16-17$ year olds). Placement type was also significantly associated with emotional problems $\left(X^{2}(3, N=230)=19.00, p=.03\right)$, with $32 \%$ of those in foster care, $30 \%$ of those in kinship care, and $81 \%$ of those in residential care being diagnosed. In addition, $21 \%$ had been diagnosed with depression or anxiety. If the figure for undiagnosed depression or anxiety is included (14\%), the overall figure rises to 35\%. Symptoms of depression and anxiety also appeared to increase through the teenage years, but reduced in early adulthood (with 7\% of 1-4 year olds, $13 \%$ of 5-11 year olds, 30\% of $12-15$ year olds, $31 \%$ of $16-17$ year olds and $25 \%$ of $18+$ year olds being diagnosed) $\left(X^{2}(15, N=233)=53.42, p=.001\right)$. A few also suffered from an eating disorder ( $5 \%$ diagnosed and 6\% undiagnosed - combined 11\%).

Over half of carers interviewed were worried about the mental health needs (including emotional and behavioural difficulties) of the child/young person they were caring for. These issues were more commonly identified than physical health needs, particularly in teenagers and young people, and for young people in residential care (75\%), and those living in foster care (56\%). In contrast, kinship carers appeared less likely to identify mental/emotional/behavioural health needs for the youth they were caring for (26\%). Two thirds of the 25 young people we interviewed reported no mental health problems in the present, or just referred to general day-to-day stress, like exams. Half of the young people recalled a time when they were feeling not as well as in the present, some of whom had experienced serious mental health problems (e.g. suicidal feelings, depression, self-harming, 
etc.). Young people attributed these positive changes in their mental health to their new situations and their supportive relationships, having grown up, or the support offered by particular formal services. Four young people were still struggling with their mental health. For instance, Nina had taken two overdoes recently, and described her mental health as "not good”; and Anna was deeply affected by guilt because of the way she entered care, and had a difficult relationship with her mother and grandmother. She had also overdosed and had been self-harming, but felt she was working through her issues, and was on the path to recovery.

\section{Help-seeking}

Professionals, carers and the young people themselves highlighted the difficulties in engaging young people in mental health and addiction services. Social work practitioners emphasised young people's lack of engagement with services as one of the factors or challenges hindering their capacity to meet the health needs of children and young people in care:

I think there are services out there but it's just the young people are not engaging because of the culture that they're in, but once they do start engaging you know it's working for them, so... there are a lot of good services... a lot of it is down to their involvement and engagement ... (Focus Group - FG1)

Some carers drew attention to young people finding it difficult to talk to somebody about their mental health. Sometimes, they stated that children and young people found it hard to talk about their feelings and their past, and they believed in the need for these young people to “open up” to somebody they felt comfortable with. Some carers were also concerned that the young people, who they cared for and had been 'emotionally damaged', refused professional help. They also felt there was a lack of effort made to encourage young people to engage with these services. 
Of the 25 young people interviewed, although the majority were able to seek help and talk to significant others (especially their families and carers) when they were not feeling mentally well, one third did not feel capable of talking about mental health difficulties with others, largely due to the stigma associated with that. These young people spoke of feelings of embarrassment, insecurity or guilt. Some understated the importance of feeling mentally unwell, arguing that it was something that eventually goes away. Two believed they never felt mentally unwell.

I usually wouldn't tell anyone about mental health issues because it's triggered by a lot of guilt, ... if I knew something was up and something was bad then yeah I would definitely tell them, but usually I just kind of deal with it myself because it passes, so usually I just keep on top of it. (Anna)

You don't feel mentally unwell for that long, well I haven't. I just get over it. Bottle it up for a couple of days and it will go away... What stops me telling people? It's just not knowing what other people would think. (Connor)

However, others talked about the importance of talking to people about their emotional wellbeing. For instance, in the past, Dylan found it very difficult to communicate anything about his mental health, but he was now beginning to talk freely to others, in particular his foster mother. He claimed that keeping these issues to oneself was very damaging. One young person, Anna, reflected that many young people experiencing mental health problems did not speak about it, did not even know they had mental health difficulties, and were unaware of any help available.

\section{Barriers to help-seeking}

Professionals, carers and young people in this study pointed out a range of barriers to helpseeking regarding mental health, including structural challenges (i.e. difficulty in accessing 
services and lack of information provided), young people’s negative feelings (e.g. stigma, embarrassment, fear, etc.), and a lack of mental health literacy (e.g. not recognising their mental health difficulties).

Young people’s feelings of embarrassment, stigma, guilt, and fear of opening up were identified by the young people themselves and their carers as obstacles for seeking help. In addition, Bridget also talked about her fear of the process of seeking help and the service itself, and the unknown ('what are they going to try and get out of me?').

However, many barriers to help-seeking had more to do with the mental health services themselves rather than the young people's resistive behaviours. For instance, some carers claimed that services were not making sufficient effort to engage the young people. Carers in children's homes stressed the fact that involving Children and Adolescent Mental Health Services (CAMHS) was not always the appropriate response. They stressed the mental health difficulties that young people living in residential care faced, and that not enough was being done to help them:

It seems to be that young people who don't readily engage with CAMHS or find it difficult to engage with CAMHS can be quite quickly discharged, whereas these are the young people with the most complex difficulties, most in need of the service and there should be greater effort maybe in trying to engage them, if you miss three appointments, forget about it ... (Residential carer 1$)$

Young people and carers also talked about professionals, in particular social workers, not spending enough time with them in order to build positive strong relationships. Although some had good experiences with professionals, others recalled damaging ones that they had with practitioners that did not take the time to know them or put pressure on them: 
... they don't take enough time and effort to actually see what's wrong, they don't get to know, they assume too much sometimes I think, maybe that's just personal experience but they assume like she or he is the same as him, so we'll keep them that way, nobody is the same ... I think they need to try and meet the individual needs of the young people.

(Bridget)

In addition, research participants talked about a range of difficulties in accessing the services needed at the right time. These difficulties related to timing issues (e.g. long waiting lists, difficulties in getting a referral, etc.), geographical/locality issues (no local services available in rural areas, having to travel, etc.), appropriateness of services, and a lack of information provided in relation to the services that are available, and where to ask for help.

Regarding timing issues, long waiting lists for mental health services was a regular issue, reported by practitioners, carers and young people. Professionals explained that young people could be waiting 14-15 weeks to have an appointment with CAMHS, and carers revealed how sometimes they never received the service at all. That could be a deterrent to seeking help in the first instance. The importance of receiving the right service at the right time was highlighted by social work and health professionals, carers and young people. If the service is not provided when needed, it may be too late for it to work when it is finally provided (as the level of need may have multiplied), the young person might have had to look for immediate short-term help elsewhere, and/or the young person might not be ready to avail of the service (at the time it is finally offered).

Takes a long time to wait for referrals. In my experience of this one time, there was too long a gap from knowing [child] was ready to talk about it, to getting an appointment. The notion would nearly leave [child] ... If I had to say that these services are fabulous, yes, 
they might well be, but I do think they have to have a quicker turnaround to be of benefit. Waiting list is too long. (Foster carer 1)

For some, it was also difficult to get a referral in the first place. Sometimes, this could be due to staff turnover (which slowed down the time to put actions in place to meet young person's needs), the lack of efficiency of the young person's social worker or social work team, or the young people not fitting the restricted criteria needed to be referred.

Regarding geographical issues, professionals identified difficulties regarding the shortage of local provision and the consequent travelling times needed to avail of specific services. This was a specific problem for LACYP that were not living in the Belfast HSC Trust, and especially those in rural areas, as well as for those that had moved jurisdictions. These young people were forced to travel long distances to access a service. This has implications for the effectiveness and responsiveness of the service, as well as for the young person's engagement.

On occasions, when a child is placed outside of the Trust area, it can be difficult accessing available resources for the young person, travelling can also take up a lot of time and impact on the amount of times you get to review the young person. (FG2)

Regarding the appropriateness of services, professionals talked about difficulties in providing the young people with the appropriate service. They believed this was because of the challenges in assessing the youth's mental and emotional wellbeing (e.g. lack of appropriate indicators and training for social workers in doing so), as well as gaps in service provision (e.g. lack of therapeutic services for children under the age of 11, lack of services for young people with ASD, lack of a regional secure mental health facility and assessment centre for children with high risk-taking behaviour and severe mental health issues, etc.). Finally, 
carers, especially kinship carers new to fostering, and some young people described a lack of information provided on the services available to them.

\section{Participants' suggestions on how to improve service provision}

In order to improve help-seeking for children and young people in care, particularly in relation to mental health services, it is important that they, their carers, and the professionals working with them, are listened to. Research participants in this study offered a range of suggestions to better engage young people in mental health services.

One recommendation was to make services more engaging. Carers talked about services needing to be more 'proactive in how they seek to support young people'. A suggestion from one young person was to create more outreach mental health support:

I would like to find a way that they could come into the house or do something that they can analyse maybe more and see exactly what you can do maybe without necessarily going to a place like that [i.e. CAMHS], because I think sometimes you don't need it, you just need somebody to talk to. ..., and you don't really want to tell people that's where you're going, whereas you can say 'I have a friend coming over', that's a lot easier to say than 'oh, I have to go to an appointment', because I didn't tell anybody in school. (Bridget)

Carers also argued about services being more locally accessible, while young people highlighted the need for more local drop-in-centres:

I think if we could bring those services in an informal way into the local area, I mean where [child] has to go to access some of them services is 15 miles away, which means [child] has to commit to being here for us to take them over and commit to being away from friends for three hours, which [child] doesn't want to do, so access, if they were local in your GP surgery, [child] might go. (Residential carer 1) 
Another key recommendation by young people and carers was more communication between health professionals. Young people commented on the frustration they felt having to retell their stories and problems over and over, which in itself discouraged them from seeking help.

... the social worker ended up sending me to three different counsellors and I keep explaining things, I couldn't keep doing that and it upset me more, ... I would be panicking, not trusting people like that. I ended up in a worse state crying and stuff, because they made me change, and I just ended up refusing to go anywhere. (Nicole) ... really the lack of communication is dreadful between each department ... it's the main problem and children have a tendency to get lost in the system ... there's not a consistent member in this child's life, one member or event two members of a staff team that would be there to see a child through and support them through it, it's not there. (Foster carer 2) As illustrated in the last quote (Foster carer 2), both professionals and carers made the case for more consistency, in the sense of having a long-lasting relationship with one professional, so the young people feel they can invest in that relationship. Professionals also suggested to improve communication between all of the agencies responsible for the child/young person, and went even further by proposing a multi-agency response, and a “joined-up approach”, in order to coordinate the individual's health needs:

It has to be a multi-agency response, it can't be in isolation, can it? ... there are other things impacting and sometimes you have to stop the other things to do the mental health issues or the emotional support, and then you have to swap to something else, so it needs timing and agreement and a proper plan, these ad hoc services coming in, it doesn't really work, does it? (FG2) 
Another suggestion was to set up a multi-disciplinary mental health team (OT specialist, clinical psychologists, specialist nurse, and educational psychologists) working in a "one-stop shop” for all children in care.

Having been provided with information on the services available and knowing where to seek help was also considered crucial by young people and carers. Some highlighted the need to give the appropriate information to young people and parents/carers, so they could seek and obtain the support they required.

There's help available but a lot of us don't know that it is there ... because nobody tells us, I mean if social services can get away with not doing something for us, they'll not do it, ... you really have to push the Trust for something that you want, instead of them actually telling you what's available. (Anna)

To sum up, key recommendations revolved around making services more locally accessible, engaging, timely/responsive, and better coordinated.

\section{Discussion}

We found that children and young people in care in Northern Ireland were experiencing high levels of mental health problems, even higher than those found in Meltzer et al.'s surveys of children in care in the early 2000s. Thus, $36 \%$ of children in our sample scored in the abnormal range in the SDQ emotional symptoms scale, 35\% had been diagnosed with emotional problems, and 21\% had been diagnosed with depression or anxiety, whereas $11 \%$, 6\% and 14\% of children in care in England, Wales and Scotland respectively had emotional disorders (Meltzer et al., 2003, 2004a, 2004b). These levels of need baldly contrast with those of the general population in Northern Ireland, as less than four per cent of all children (0-18 
years old) have learning or behavioural difficulties, and less than one per cent suffer from mental health difficulties (NI Census, 2011).

Regarding help-seeking, the children and young people in our sample were more likely to seek help from family and friends rather than from formal services, which is consistent with findings from other studies (Anderson \& Lowen, 2010; Tylee et al., 2007). Although young people’s feelings and attitudes towards their mental health and help-seeking (e.g. stigma, embarrassment, self-reliance, etc.) featured among the barriers for them seeking help, a number of structural barriers related to the delivery of services were also identified. These included difficulties in accessing the services needed (due to long waiting lists, difficulties in getting referrals, lack of local services - having to travel, etc.); services/professionals not taking the time to encourage young people and making them feel comfortable; lack of communication between professionals; and lack of information provided to young people and their carers regarding mental health and services available. In the UK, some of these structural barriers have been confirmed in policy and research documents, including stringent and narrow criteria for over-stretched services, lack of communication and collaboration at the CAMHS and AMHS interface (Royal College of Psychiatrists, the Mental Health Network, NHS Conferderation, \& London School of Economics and Political Science, 2009), and disconnectedness of the settings where young people seek help from (e.g. schools, clinics, etc.) (Malla, Iyer, McGorry et al., 2016)

The solutions often given were: to provide more outreach work; to make services more accessible, in terms of being in the local area, more flexible and "less formal”; to extend the upper age limit of CAMHS to 21 (and possibly older); to provide more and better information on services available; services having a more integrated approach, and promoting interagency communication; and to enable, train and encourage professionals to develop positive trusting relationships with the young people. Some of these recommendations have appeared 
in recent policy documents. In Northern Ireland, the DHSSPS (2010)’s strategy for the development of psychology therapy services, recommended to provide the public, service users and clinicians with information on the range of psychological therapy services available and how to access them, and the DHSPSS (2012)'s CAMHS service model proposed targeted support for the needs of children who are vulnerable and marginalised, with also specific focus on supporting parents and carers. In the UK, a more integrated service provision has also been proposed, in order to remove duplication and overlap, and work in close partnership, sharing infrastructure and resources (Faulconbridge et al., 2016). In addition, some examples of good practice which take some of these ideas on board have been highlighted. For instance, a local initiative in Birmingham to develop a dedicated youth mental health service has exhibited capacity in engaging young people through rapid response, high quality initial assessments, and lower drop-out rates than community mental health teams (Malla et al., 2016).

Within the context of recession and the tightening of public spending, concentration of services in fewer sites might be one solution proposed, with smaller local services and specialist services being threatened, and outreach work being considered as too expensive (Royal College of Psychiatrists et al., 2009). However, in our study, this type of services such as mentoring schemes, local drop-in centres, health promotion (using art and activitybased sessions) in residential care homes, home visiting by clinical psychologists (outreach work) - appeared to be much more effective in engaging young people than larger formal sites in the capital. Given the high economic costs of mental health problems later in life and thus the importance of early intervention, effective and engaging services for young people (especially those particularly vulnerable to mental difficulties, such as the looked after population) are essential in the long-term. 


\section{Conclusion}

Although the findings from this study are similar to those found in other studies in the UK and further afield, they offer a baseline for the looked after population in Northern Ireland, and provide further evidence of the high level of mental health difficulties that young people in the care system experience, and on the barriers they encounter to seek and receive help from services. In view of some of the suggestions made by young people, their carers, and professionals, we recommend that more effort should be made by mental health services to engage young people. Investing in these services would be cost effective, thus could save the UK and (in this case, the Northern Irish) economy in welfare and criminal costs, as mental ill health in childhood and adolescence causes short- and long-term negative consequences, particularly when left untreated, treated too late, or inadequately treated (Malla et al., 2016).

As it has been widely claimed, it is vital that mental health services are planned and offered taking into account service users’ views and recommendations, as their engagement is crucial for their successful delivery (Dalton, Chambers, Harden et al., 2016). This is especially the case with young people in the care system, who might often feel disempowered and have little control of their lives, and whose emotional wellbeing should not be overlooked.

\section{Acknowledgements}

We would like to thank the Executive Office (TEO) in Northern Ireland (formerly the Office of the First Minister and Deputy First Minister) for funding this research, and giving permission to re-use material from the research report. 


\section{References}

Anderson, J. E., \& Lowen, C. A. (2010). Connecting youth with health services: Systematic review. Canadian Family Physician, 56(8), 778-784.

Anderson, J.E., Spencer, N., \& Vostanis, P. (2004). The health needs of children aged 6-12 years in foster care. Adoption \& Fostering, 28, 31-40.

Beck, A. (2006a). Addressing the mental health needs of looked after children who move placement frequently. Adoption \& Fostering, 30(3), 60-65.

Beck, A. (2006b). Users' views of looked after children's mental health services. Adoption \& Fostering, 30(2), 53-63.

Clement, S., Schauman, O., Graham, T., Maggioni, F., Evans-Lacko, S., Bezborodovs, N., Morgan, C., Rüsch, N., Brown, J.S.L., \& Thornicroft, G. (2015). What is the impact of mental health-related stigma on help-seeking? A systematic review of quantitative and qualitative studies. Psychological medicine, 45(01), 11-27.

Dalton, J., Chambers, D., Harden, M., Street, A., Parker, G., \& Eastwood, A. (2016). Service user engagement in health service reconfiguration: a rapid evidence synthesis. Journal of health services research \& policy, 21(3), 195-205.

DH (2007). Mental Health: New Ways of Working for Everyone. Developing and sustaining a capable and flexible workforce. Progress Report, July 2007. London: Department of Health.

DHSSPS (2010). A strategy for the development of psychological therapy services. June 2010. Belfast: Department of Health, Social Services and Public Safety.

DHSSPS (2012). Child and Adolescent Mental Health Services. A service model. July 2012. Belfast: Department of Health, Social Services and Public Safety. 
Egelund, T., \& Lausten, M. (2009). Prevalence of mental health problems among children placed in out-of-home care in Denmark. Child \& Family Social Work, 14(2), 156-165.

Faulconbridge, J., Gravestock, F., Laffan, A., Law, D., O’Curry’s, S., Taylor, K., Taylor, J., \& Zlotowitz, S. (2016). What good could look like in integrated psychological services for children, young people and their families: Preliminary guidance and examples of practice. Child \& Family Clinical Psychology Review, 4.

Ford, T., Vostanis, P., Meltzer, H., \& Goodman, R. (2007). Psychiatric disorder among British children looked after by local authorities: comparison with children living in private households. The British Journal of Psychiatry,190(4), 319-325.

Golding, K. S. (2010). Multi-agency and specialist working to meet the mental health needs of children in care and adopted. Clinical Child Psychology and Psychiatry, 15(4), 573-587.

Green, H., McGinnity, A., Meltzer, H., Ford, T., \& Goodman, R. (20014). Mental health of children and young people in Great Britain, 2004. Office for National Statistics: HMSO.

Gulliver, A., Griffiths, K. M., \& Christensen, H. (2010). Perceived barriers and facilitators to mental health help-seeking in young people: A systematic review. BMC Psychiatry (Open Access), 10, 113.

Kauer, S. D., Mangan, C., \& Sanci, L. (2014). Do online mental health services improve help-seeking for young people? A systematic review. Journal of medical Internet research, 16(3), e66.

Lehmann, S., Havik, O. E., Havik, T., \& Heiervang, E. R. (2013). Mental disorders in foster children: a study of prevalence, comorbidity and risk factors. Child and adolescent psychiatry and mental health, 7(1), 1. 
Malla, A., Iyer, S., McGorry, P., Cannon, M., Coughlan, H., Singh, S., Jones, P., \& Joober, R. (2016). From early intervention in psychosis to youth mental health reform: a review of the evolution and transformation of mental health services for young people. Soc Psychiatry Psychiatr Epidemiol, 51, 319-326.

McSherry, D., Fargas Malet, M., McLaughlin, K., Adams, C., O'Neill, N., Cole, J., \& Walsh, C. (2015). Mind Your Health: The physical and mental health of looked after children and young people in Northern Ireland. Belfast: Queens University Belfast.

Meltzer, H., Corbin, T., Gatward, R., Goodman, R. \& Ford, T. (2003). The mental health of young people looked after by local authorities in England. London: Office of National Statistics.

Meltzer, H., Lader, D., Corbin, T., Goodman, R. \& Ford, T. (2004a). The mental health of young people looked after by local authorities in Scotland. Edinburgh: The Stationery Office.

Meltzer, H., Lader, D., Corbin, T., Goodman, R. \& Ford, T. (2004b). The mental health of young people looked after by local authorities in Wales. London: The Stationery Office. Mullan, C., Rollock, F., McAlister, S., \& Fitzsimons, L. (2007). “Don’t be so formal, I’m normal": A research report on the mental health of looked after children/care leavers in Northern Ireland. Belfast: VOYPIC.

Oswald, S. H., Heil, K., \& Goldbeck, L. (2010). History of maltreatment and mental health problems in foster children: A review of the literature. Journal of Pediatric Psychology, 35(5), 462-472.

Patel, V., Flisher, A.J., Hetrick, S., \& McGorry, P. (2007). Mental health of young people: a global public-health challenge. Lancet, 369, 1302-13013. 
Plaistow, J., Masson, K., Koch, D., Wilson, J., Stark, R. M., Jones, P. B., \& Lennox, B. R. (2014). Young people's views of UK mental health services. Early intervention in psychiatry, 8(1), 12-23.

Rickwood, D. J., Deane, F. P., \& Wilson, C. J. (2007). When and how do young people seek professional help for mental health problems. Med J Aust, 187(7 Suppl), S35-S39.

Rothí, D. M., \& Leavey, G. (2006). Mental health help-seeking and young people: A review. Pastoral Care in Education, 24(3), 4-13.

Royal College of Psychiatrists, Mental Health Network, NHS Confederation, \& London School of Economics and Political Science (2009). Mental health and the economic downturn. National Priorities and NHS solutions. London: Royal College of Psychiatrists.

Samuels, G. M., \& Pryce, J. M. (2008). “What doesn't kill you makes you stronger”: Survivalist self-reliance as resilience and risk among young adults aging out of foster care. Children and Youth Services Review, 30(10), 1198-1210.

Sempik, J., Ward, H., \& Darker, I. (2008). Emotional and behavioural difficulties of children and young people at entry into care. Clinical child psychology and psychiatry, 13(2), 221233.

Singh S., Paul, M., Ford, T. et al. (2010). Process, outcome and experience of transition from child to adult mental healthcare: multiperspective study. Br J Psychiatry, 197, 305-312.

Taggart, L., Cousins, W., \& Milner, S. (2007). Young people with learning disabilities living in state care: Their emotional, behavioural and mental health status. Child Care in Practice, 13(4), 401-416.

Tarren-Sweeney, M. (2008). The mental health of children in out-of-home care. Current opinion in psychiatry, 21(4), 345-349. 
Teggart, T., \& Menary, J., (2005). An investigation of the mental health needs of children looked after by Craigavon and Banbridge Health and Social Services Trust. Child Care in Practice, 11, 39-49.

Tylee, A., Haller, D. M., Graham, T., Churchill, R., \& Sanci, L. A. (2007) Youth-friendly primary-care services: How are we doing and what more needs to be done? The Lancet, 369, 9572, 1565-1573.

Vanheusden, K., Mulder, C. L., van der Ende, J., van Lenthe, F. J., Mackenbach, J. P., \& Verhulst, F. C. (2008). Young adults face major barriers to seeking help from mental health services. Patient Education and Counseling, 73(1), 97-104.

Vostanis, P., Bassi, G., Meltzer, H., Ford, T., \& Goodman, R. (2008). Service use by looked after children with behavioural problems: Findings from the England survey. Adoption \& Fostering, 32(3), 23-32.

Zwaanswijk, M., Verhaak, P. F. M., Bensing, J. M., van der Ende, J., \& Verhulst, F. C. (2003). Help-seeking for emotional and behavioural problems in children and adolescents. Springer Berlin /Heidelberg. 